\title{
La frontera de la frontera: sociedad indígena costarricense, 1800-1830
}

\author{
María E. Bozzoli
}

Profesora emérita de la Escuela de Antropología, Universidad de Costa Rica, San José, Costa Rica

MARIA.BOZZOLI@ucr.ac.cr

\begin{abstract}
Resumen: Se parte de que en el momento de la Independencia (1821) Costa Rica era una sociedad de frontera, por haber sido región fronteriza de la jurisdicción colonial española en general y específicamente de la Capitanía General de Guatemala. Al emanciparse, en la construcción de la estatalidad desarrolla la centralidad, la que a su vez se estructura en centro y periferia. La periferia es frontera en el sentido sociocultural (indígenas separados socialmente como inferiores) y en el sentido geográfico (en las márgenes urbanas o en la vasta zona fronteriza muy alejada de los poblados hispano criollos). La administración colonial creó los pueblos reducidos; se diferencian los más cercanos a los centros urbanos de aquellos colindantes con la zona fronteriza; las etnias independientes en esta zona y los pueblos cambian, a diferentes ritmos, su condición de frontera, después de 1821. La frontera separa pero también permite la interacción, la permeabilidad.

Palabras claves: Frontera; sociedad finicolonial; emancipación; indígenas.
\end{abstract}

The borderland peoples of the border country: Costa Rican Indigenous Society, 1800-1830

Abstract: At the time of emancipation (1821), Costa Rica was a frontier society. It had been the border region of the Spanish colonial dominions in Central America, specifically of the Captaincy General of Guatemala. Upon emancipation, state building creates centrality which in turns develops into center and periphery. The periphery is a frontier in the socio cultural sense (indigenous people are socially separated as inferiors) and in the geographic sense (at the margins of urban areas or in the vast border zones very

Cuadernos de Antropología

Enero-Junio 2016, 26(2), 91-120

DOI: $10.15517 /$ cat.v26i2.26492

Recibido: 29-03-2016 / Aceptado: 13-06-2016 / Publicado: 13/12/2016

Revista del Laboratorio de Etnología María Eugenia Bozzoli Vargas

Escuela de Antropología, Universidad de Costa Rica

http://revistas.ucr.ac.cr/index.php/antropologia

ISSN 2215-356X 
far from Hispanic towns). Colonial administration gave rise to "reducciones", that is, it created indigenous mission towns; indigenous settlements differ if they are close to urban centers or if they are next or within borderlands; after 1821 the more independent latter ones and the former ones close to Spanish towns change their frontier status at different rythms. Frontier conditions separate native people from the Spanish descendants and mestizo people, but they also allow for interaction between them.

Keywords: Border; frontier; colonial society; emancipation; Costa Rican indigenous people.

La sociedad costarricense en los albores de la emancipación presenta un conjunto de rasgos propios de sociedades fronterizas, derivados del hecho de haberse desarrollado Costa Rica en la frontera de la jurisdicción colonial española en general y específicamente de la Capitanía General de Guatemala. Previo a 1821 las áreas costarricenses donde vivían indígenas denominados gentiles o infieles eran consideradas las zonas limítrofes de las mencionadas jurisdicciones (Bozzoli, 2005); estas zonas siguen siendo periferia de una sociedad que en sus primeros años de centralidad conserva rasgos previos de sociedad fronteriza.

En el trabajo de 2005 incluí un decreto de 1824 posterior, ilustrativo de la nueva definición oficial de los limítrofes:

Los pueblos indígenas que nos rodean tienen los mismos derechos que nosotros... Ultimamente, las ideas del día y progresos en todas las líneas de nuestro Estado exigen la franqueza y comunicaciones universales de nuestros pueblos con todos los del mundo si fuese posible, y a lo menos con los limítrofes ... Observando que importa mucho a los pueblos del Estado, y sin intereses quitar toda enemistad con los limítrofes creada por el gobierno español, y abrir francas comunicaciones y relaciones con ellos ... decreta- 1. Cesen desde la publicación de este decreto todos los establecimientos del gobierno Español para conquistar los indígenas vecinos de este Estado. 2. Los pueblos conquistados siguen bajo el gobierno del Estado ... 3. Estos pueblos y los demás del Estado son libres en el comercio... (Carrillo y Zeledón, 1962, pp. 9-10).

En el presente trabajo examino en mayor detalle la situación de frontera de los grupos indígenas inmediatamente antes y después a la Independencia; con la independencia la sociedad costarricense pasó de ser frontera (según solían ser las fronteras nacionales hasta mediados del siglo XX), a condición de centralidad, pero en la centralidad tuvo a su vez centro y periferia. En la periferia social y geográfica se encuentran los indígenas. 


\section{Costa Rica en su condición de frontera y en la de centralidad o construcción de la estatalidad}

Lo siguiente es un resumen de situaciones inmediatamente previas a 1821 correspondientes al carácter fronterizo de Costa Rica, en relación con el Reino de Guatemala y España, y de la situación inmediatamente posterior a la Independencia ${ }^{1}$ :

1. Escasa población: En 1821 la población de C. R. aproximaba 60000 habitantes y en 1824 tenía, según censo, 65393 personas. La población aumentó en forma muy gradual; se calculó en 303762 en 1900.

2. Prolongada situación de zona fronteriza: Desde el inicio hasta el final de la Colonia, cuando existe como "gobierno político y militar de Costa Rica", adscrito a la Intendencia de León.

3. Conjunto de condiciones consideradas desventajosas: la más pobre, menos poblada, la de tecnología más rudimentaria, con predominio de la producción de subsistencia, mercados interno y externo limitados, falta de población indígena, ausencia de minas, falta de vías de comunicación, política mercantilista adversa, negligencia de autoridades, falta de moneda en circulación, capitales limitados, y falta de mano de obra. Cambios graduales a partir de 1821 en algunos de estos aspectos.

4. Autonomía: enraizada en la necesidad de resolver la provincia por sí sola sus propios problemas, una de cuyas manifestaciones es el variado accionar de cabildos y ayuntamientos. Coadyuvantes de la autonomía, son "la libertad personal y el acceso a la tierra conquistados por el campesinado [no indígena] en el siglo XVIII” (Acuña y Molina, 1991, p. 52). Se afianza después de 1821.

5. Economía no integrada: tres regiones, bastante separadas: la de ganadería extensiva al oeste, el cacao, decadente, en Matina; labores agrícolas, pecuarias y artesanales en el Valle Central. Cambios a partir de 1821.

6. Indígenas escasos y dispersos. En 1801, constituían el 14\% de la población de Costa Rica (8 281); 2630 "indios sin reducir", "limítrofes". El Censo de 1824 muestra una relación menor de diez por ciento de indígenas en pueblos en relación con la población total no indígena. Terrenos y bosques de indígenas, percibidos sin dueños o sin ocupantes, o afectados por la idea de que el no indígena tenía prioridad sobre la tierra, apropiados por el campesinado libre. Situación continúa en el perídodo republicano.

7. Campesinado libre: Frontera agrícola. La familia campesina, no indígena, prevalecía numéricamente; escaso control de factores naturales, como los climáticos, plagas, o enfermedades de cosechas, animales y gente. Aunque los indígenas campesinos no libres, eran un porcentaje menor, se agregan a los libres después de 1821, y el predominio del campesinado se prolonga hasta después de mediados el siglo XX.

8. Mundo urbano en cierne: núcleos urbanos muy limitados en obras de urbanismo, y en población; los comerciantes son la categoría urbana más prominente; escasa burocracia, igualmente urbanizada. Ambos

1 El anexo 1 contiene la bibliografía citada en Bozzoli (2005), de la que se derivaron estas características. Se ofrece dado que la ponencia citada es inédita. 
son explotadores y extractores del excedente de los labriegos, pero igualmente, son el penúltimo eslabón en la cadena de explotación que viene desde el centro rector. Cambio gradual después de 1821 .

9. Más limitada burocracia. No estaban presentes en la región fronteriza muchos representantes del gobierno del Reino. Lo eclesiástico proporciona otro ejemplo: menor poder y menor presencia. Cambio gradual después de 1821, la Diócesis data de 1850.

10. Dependencia de centros, necesitaba de vínculos externos: exportaciones a Centroamérica, a Cartagena, Portobelo y Panamá, Mexico, etc. Importación de textiles, adornos, y joyas. Después de 1821, búsqueda de vínculos externos más favorables y énfasis en industrias propias

11. Predominio de la comunicación oral. Se instala imprenta en 1830. Las mismas gentes interactuaban cara a cara en las iglesias, las fiestas, las tertulias, el mercado, y otras situaciones. Después de 1821 alfabetismo aumenta muy gradualmente.

12. Mayor nivelación social que en los centros rectores. Estratificación y procesos de exclusión típicos de la situación colonial, aunque con alguna nivelación. Después de 1821 la nivelación social persiste si se compara con países vecinos. Obviamente, la pequeña elite más adinerada se mantiene y aumenta gradualmente.

Después de la Independencia, con la nueva conciencia de la territorialidad, se reorganizaron las relaciones centro-periferia, se escogió nueva capital (San José). La creciente autonomía es identificable en acciones como la adopción de constitución, decreto de libre comercio, atención de caminos hacia los puertos, etc. En contraste con la Colonia, se intensificó un producto exportable de suficiente éxito permanente como fue el cultivo del café. Se marcó, aunque gradualmente, la creciente urbanización, la búsqueda del modelos para relacionarse con los países vecinos (nueva relación "nosotros-otros"), sobrevino mayor monetización como alternativa al intercambio por trueque. Hubo aumento de la inmigración de comerciantes y profesionales. Los indígenas fueron considerados ciudadanos, pero los de las zonas fronterizas, que estaban más allá del Valle Central, entre éste y los límites con Nicaragua, Panamá, y los océanos, también permanecieron "limítrofes"; eran etnias subordinadas en la periferia, aunque por su aislamiento, mantuvieron condiciones para llevar una vida bastante independiente de centros urbanos y gobierno nacional. Se mantuvo la política de evangelizarlos y "civilizarlos"; los cercanos a zonas urbanas participan como campesinado libre (en la Colonia eran un campesinado de comunidad corporativa), aunque vistos diferentes por su origen y rasgos culturales indígenas, incluso hasta entrado el siglo XX.

\section{Situación indígena al final de la colonia}

Los indígenas se encuentran en una Costa Rica similar a la siguiente, descrita por Florencio del Castillo en 1813: 
Hay actualmente en ella 22 pueblos, doce de ellos son Indios y los demás de Españoles blancos y de color, á demás de una multitud de Chácaras, haciendas y Caseríos distantes de los expresados pueblos... hay pueblos que distan entre sí ciento y cincuenta leguas.

El número de los habitantes es de 60 á 70 mil... . Además de esta población hay en su territorio tres Naciones de Indios gentiles que habitan las montañas y Costas del Norte, las cuales se conocen con los nombres de Indios de la Talamanca, Indios del Norte $\mathrm{y}$ Indios Mosquitos, todas tres bastante numerosas. Por estas razones Costa Rica siempre fue considerada y tenida desde su descubrimiento por Provincia separada é independiente de las otras, gobernada en lo político y militar por un Gefe con el título de Gobernador y Comandante de las armas, el cual no conoce más dependencia que de la Audiencia y Capitanía General de Guatemala; por manera que sólo en lo Eclasiástico ha estado agregada á la Diócesis de Nicaragua (del Castillo, 1907, p. 412).

Del mismo modo que del Castillo (1907) diferencia los indígenas en "pueblos”, de aquellos en las "naciones de indios gentiles", la información sobre indígenas de 1800 a 1830 hace necesario mantener estas dos categorías generales: son diferentes, tanto en la Colonia como después de ella. Los pueblos tuvieron origen en las reducciones efectuadas por la administración colonial, con propósitos de evangelización y tributación; el efecto estructural fue crear un campesinado indígena de comunidad corporativa, para cumplir con ciertas obligaciones hacia los dominadores coloniales. El devenir de estos indígenas fue diferente al de los indígenas "de la montaña", denominados gentiles, en relación con las tierras, su cristianización, su transculturación, y articulación con la nación-estado. No obstante que los indígenas en las montañas eran subordinados, tanto en su condición de limítrofes coloniales como republicanos, su situación estructural es diferente; no fueron campesinos sino etnias de cultivadores independientes (otro nombre que se ha aplicado es tribu); podían sobrevivir sin ninguna o muy escasa relación con ciudades y dominadores; se manejaron en relativamente gran independencia y resistencia, algunos sectores de ellos hasta el siglo XX inclusive.

\section{Sobre los pueblos de las reducciones}

La población de los pueblos reducidos solía ser menor de 700 personas en cada uno. Fray Francisco Reygada (1907) documenta para 1797 San José de Orosí (674 habitantes); San Francisco de Térraba (469 habitantes); N.S. de Guadalupe, [formado con indígenas térrabas] (158 habitantes); y Tres Ríos, con 437 en 1743. Barrantes (2004), con base en Monseñor B. A. Thiel (1902), relata que Boruca contaba en 1801 con alrededor de 250 habitantes; Térraba con Guadalupe, en 1805, con 350. Barrantes (2004) igualmente cita a Fray Juan de Dios Campos Díez quien informó en 1802, para Boruca, 236 habitantes, 41 viviendas. 
El devenir de los pueblos reducidos, sujetos a tributo u otras obligaciones económicas, a su vez es diferente para los del núcleo de centros urbanos del "Valle Central" y los pueblos en el borde de las zonas fronterizas de mayor alejamiento del núcleo urbano, en adelante denominados “colindantes".

En la primera subcategoría se encuentran Pacaca (aunque al borde del valle), Aserrí, Curridabat, Tres Ríos (La Unión); Orosi (del Valle, pero con mayor acceso a "la montaña"), Laborío, Cot, Quircot, Tobosi, Barva; a estos se les puede aplicar la noción de frontera sociocultural en su relación con los no indígenas, y en diferentes medidas, geográfica, porque siempre existe alguna distancia y demarcación territorial con respecto a los asentamientos hispano criollos (mestizos o ladinos, criollos y españoles); en la segunda subcategoría, se encuentran Boruca, Térraba, Guadalupe, muy alejados del Valle Central; y Atirro y Tucurrique, alejados de los centros, al borde del Valle; participan no solo en una frontera sociocultural, sino también están en una de lejanía, colindante con la zona fronteriza Norte y Caribe, donde están los indios de "la montaña". Estas comunidades corporativas son campesinado en el tanto que dependen del Estado en las leyes para gobernarse, y de la Iglesia Católica en la religión, pero son sumamente escasos sus vínculos con centros urbanos; no fueron periferia circundante de esos centros sino hasta el siglo XX; su economía fue principalmente de autosuficiencia. Entonces, es diferente lo que aplica en el núcleo del Valle Central de lo que aplica a los colindantes, porque su situación de frontera difiere: a manera de ejemplo, se ofrece la información siguiente aplicable a los pueblos del Valle Central más cercanos a los centros urbanos:

\section{Sobre los pueblos del núcleo del Valle Central}

La ubicación estratégica de las tierras y la calidad de los suelos no solo les permitió a los indígenas del Valle Central de Costa Rica cultivar sus predios, sino también arrendar parte de ellos a campesinos criollos de origen español, denominados por los indígenas ladinos. Con el dinero obtenido por concepto de arrendamiento de tierras (terrajes), los indígenas cancelaron parte del tributo real que les correspondía a todos los indios varones mayores de 25 años. De esta forma, el tiempo que usualmente se destinaba a la búsqueda del dinero para pagar el tributo fue utilizado en el desarrollo de actividades familiares o colectivas, sin que tampoco se diera un proceso de diferenciación económica importante al interior de las comunidades indígenas" (Bolaños, 1998, p. 155). 
En la misma fuente se lee:

La lucha de los indígenas del Valle Central costarricense se centró en evitar la entrada ... del mestizo pobre sin tierra y controlar ... a los ladinos ... que reclamaban ... tierras indígenas. ... Con relativo éxito los indígenas enfrentaron la expropiación de sus tierras durante la última etapa del período colonial, las que fueron medidas varias veces a solicitud de los mismos indígenas (Bolaños, 1998, p. 156).

Margarita Bolaños (1998) también afirma: "Los indígenas del Valle Central hablaban el español desde el siglo XVII, no usaban traje distintivo y las instituciones cívico-religiosas como las cofradías no alcanzaron el poder ni la importacia que tuvieron ... en Mesoamérica” (p. 165).

Respecto a sus posibilidades para tributar, siempre fueron difíciles: Don Tomás de Acosta (1907b) informa que son 8 los pueblos tributarios en la gobernación, siendo los que tributan 340 personas. Agrega que pagan en plata. Se refiere a sus dificultades para vender sus cosechas de maíz y hortalizas. El Gobernador Juan de Dios de Ayala (1907b), informa:

A los indios les he hecho comprender la obligación que tenemos todos los vasallos de contribuir al rey para los gastos del Estado; y habiéndoles reiterado la real cédula en que S.M. reestablece el pago del tributo, se ha manifestado muy gustosos con esta soberana disposición, asegurándome que se mantendrán siempre fieles á la monarquía. Las doctrinas de estos pueblos se hallan en el mejor orden y no menos las escuelas de primeras letras, habiendo determinado para su permanencia y que sus dotaciones sean fijas, se paguen de los fondos del común, que también he hecho reestablecer, haciendo que todos los granos se siembren que respectivamente producen sus tierras (p. 508).

El Gobernador de Acosta informó, en 1802, sobre las subdelegaciones de justicia de pueblos tributarios del Valle Central: Currirabá, Asserry, Pacaca, Barva, Laborío, Cot, Quircot y Tobosi. Las personas tributarias suman 328, pagan algo más de un peso anualmente, pero también pagan en plata el diezmo y comunidad (de Acosta, 1907c). 
De acuerdo con Barrantes Cartín, la jurisdicción de Aserrí y Curridabat formaba un solo curato atendido desde los orígenes de la Colonia por los Observantes; el oratorio construido en 1821 estuvo a cargo de un franciscano. En 1818 los Observantes entregaron varios curatos a los seglares, entre ellos Aserrí y Curridabat, pero aunque pasaron a la jurisdicción del ordinario, siguieron proveídos por religiosos (Barrantes, 2004).

\section{Caso del pueblo Tres Ríos (La Unión, Nuestra Señora del Pilar)}

En 1771, el poblado tenía una iglesia, un convento; 45 casas, un cabildo. En 1801 la población es mayoritariamente indígena, seguida de mestizos y ladinos, y de españoles; es interesante que el tributo de pita

y de hilo morado en realidad no era un recurso propio sino de indígenas cercanos al mar muy alejados de Tres Ríos:

1801: La población total de Tres Ríos es de 364 personas. En la que hay 15 españoles, 55 mestizos y ladinos y 212 indios.

1808: El 12 de mayo el gobernador de Cartago en representación de los indios de Tres Ríos solicita al Gobernador Superior suspender el pago en especie porque tenían que ir hasta Matina y Boruca a buscar las 20 libras de pita y las 2 libras de hilo morado que tenían como tributo. Se acordó que en su lugar pagaran 27 pesos en dinero al año (Durán, 2013, prf. X).

\section{Los pueblos colindantes con la zona fronteriza, es decir, con "la montaña"}

Los datos siguientes ilustran algunos aspectos de la vida cotidiana de los pueblos colindantes con "la montaña" (aplica también a Orosi en este caso):

\section{La religion}

Refiriéndose a pueblos reducidos colindantes, San José de Orosí, San Francisco de Térraba, y N.S. de Guadalupe, Fray Francisco Reygada (1907) apunta:

...se ha procurado establecer el idioma Castellano, ... y le hablan los Indios ... confiesan y repiten la doctrina Cristiana, sin embargo que usan también las lenguas 
nativas y por lo regular las transfieren a sus hijos, del mismo modo que se verifica en las Montañas, más no por eso están escasos de instrucción en lo tocante a nuestra creencia, sino que saben lo suficiente para recibir Sacramentos y practicar actos de religión, asistiendo a los oficios divinos, oyendo misa con frecuencia, rezando todos los días el rosario ... confesando y comulgando algunas veces al año, señaladamente en el tiempo de Pascua Florida y Natividad de los Santos del nombre de cada uno. En los dichos pueblos ... entierran sus muertos religiosamente, hacen ofrendas de Plátanos, Pijibai, Cacao y otros frutos el día de la conmemoración de todos los difuntos y los Lunes del año en que se acostumbra cantar responso por las ánimas del Purgatorio. Muchos trabajan con diligencia para que se les digan Misas y Responsos después de su muerte, criando con ese obgeto Marranos, Gallinas y otros animales domésticos, y ya ha habido Indio que deje ocho reales en plata con este piadoso destino (pp. 258-259).

El gobernador Tomás de Acosta (1907f) informa sobre los pueblos colindantes; nótese que por acceso a zona fronteriza, Orosi, participa de algunos rasgos "colindantes".

...el estado actual de las reducciones de Atirro, Tucurrique y Boruca, que están a cargo de religiosos observantes de la provincia de San Jorge de Nicaragua, y las de Orosi, Térraba y Guadalupe, que lo están á los del colegio de Cristo de esa capital, debo decir que por lo que toca á las dos primeras de dichas reducciones y desde el año de 1797 ... sólo ha salido de la montaña un indio, que voluntariamene vino buscando el Cristianismo, y han profugado once para volver al Gentilismo. La diferencia de los diez que resultan de menos á la Cristiandad puede provenir de las pocas entradas que los reductores de Atirro y Tucurrique han hecho á la montaña, de la innata inclinación de los indios á la vida holgazana y licenciosa de las aldeas... de las ningunas proporciones que tienen los reductores ... de San Jorge para atraerse con dádivas á los que quieren convertir ni socorrer á los ya convertidos, ... del modo... rígido de tratar á los recién convertidos y principalmente sobre puntos de religión, ó en fin, de que sólo sacando los párvulos de la montaña podrán ser buenos Católicos (p. 297).

En 1802 Fray Juan de Dios Campos Díez informa que Boruca cuenta con iglesia sin adornos y convento de paja. En el común (terreno para iglesia y comunidad) posee "24 reses, una mula, dos caballos y un efectivo de tres pesos y dos reales, en tanto que el convento tenía 39 reses” (Barrantes, 2004, p. 33). En 1804 Fray Juan se queja al gobernador de que: 
...dos indias de Boruca hacían maleficios y practicaban brujerías, y que una de ellas tenía dos piedras, de la redondez y tamaño de un peso fuerte, que cuando las soplaba respondían por los acontecimientos futuros. ...decía que habiendo ido hacia la costa... halló varios ídolos de piedra... y que no descansó hasta dejarlos todos desfigurados... (Barrantes, 2004, p. 33-34).

Sobre disposición de bienes del común, en 1809 un ejemplo de procedimiento fue que el gobernador dispusiera "la venta de 20 reses del común que produjeron $\$ 104$, dinero que ... el alcalde de Térraba entregó al Sr. Antonio Figueroa, quien los empleó en pagar \$70 al cura, al sacristán mayor y al arponero y el saldo se utilizó en comprar vino, cera, pan, y otras cosas para el servicio de la iglesia" (Barrantes, 2004, p. 62).

De los bienes de Orosi en 1815 se dijo: “...está completamente provisto de templo, sagrados utensilios, imágenes adornos, habitaciones para los venerables padres e indios, ganados, bienes y fierros de común, igualmente que lo está el ya mencionado pueblo de Térraba” (Barrantes, 2004, p. 64).

\section{La educación}

Los Misioneros siempre dedicaron tiempo a la enseñanza de artes y oficios, y dar alguna escolaridad, con diferencias para hombres y mujeres: "les enseñan a leer el Castellano, y el latín á los que se destinan para Sacristanes y cantores; pero son muy raros los Indios que aprenden a escribir. A las mugeres se les enseña á Texer, coser, lavar, cocinar y servir en los demás oficios comunes de las casas y ninguna se aplica a leer" (Reygada, 1907, p. 259).

\section{Organización política y justicia}

La Política de estos pueblos [los colindantes] "es casi la misma que se observa en los otros del Reyno que están ya plenamente Civilizados [los del Valle Central]. Hay Gobernadores, Alcaldes, Regidores, Fiscales y demás empleos subalternos, que se mudan anualmente por elección pública ... salvo la de Gobernador, cuyo empleo confieren los Padres Misioneros al Indio más despejado y dura por el tiempo que les 
parece conveniente. Por medio de estos Ministros se castigan los delitos... adulterio, robo y otros desórdenes ... á cada vicio las penas de axotes, zepo, trabajos públicos y otras ... El estrupo (sic) ó acceso a Muger virgen lo miran los Indios con horror, y aunque se comete raras veces, lo castigan con más severidad... entre ellos la Muger corrompida casi siempre persevera despreciada, de manera que ninguno quiere recibirla por Esposa (Reygada, 1907, p. 259).

La Junta Gubernativa, en 1823, después de la Independencia, ordenó cambiar penas coloniales, lo que permite saber cómo eran:

...ordenó que en Boruca se prohibiera totalmente la pena de azotes, terrible costumbre que era practicada por las autoridades locales y consentida por los misioneros. En esa ocasión mandaron a retirar las picotas, grillos, esposas y cepos que usaban para dar tormento a los infelices indígenas. Eso también se practicaba en Térraba y pasaron años para erradicarlo.

Cuando ocurre la independencia de España, Boruca y Térraba dependen en lo civil del Gobernador de Cartago, en tanto que eclesiásticamente Boruca depende del Convento de San Francisco y Térraba del Convento de Orosi (Barrantes, 2004, p. 106).

\section{Matrimonio, bautismo, entierro}

Reygada (1907) expresa que "[Los] Padres naturales solicitan con gran desvelo colocar sus hijos en matrimonio luego que tienen edad competente para celebrarlo ...á causa de ser los Indios tan reverentes a sus Padres, perseveran bajo de su potestad después de Casados y Velados...” (p. 259).

De los pueblos de Atirro y Tucurrique, entre 1797 y 1803, informa de Acosta (1907f, p. 295) catorce casamientos, cuarenta y seis bautismos y veintidos entierros. La población de ambos pueblos es, en 1803, de 64 en el primero y 111 en el segundo.

Del pueblo de Boruca comunica Fray Juan de Dios Campos Díez que "cuando un indio se casaba los hermanos tenían derecho a usar de su mujer, y cuando estaban ebrios por exceso de consumo de chicha cambiaban sus mujeres" (Barrantes, 2004, p. 34). 


\section{División del trabajo}

Los varones de estos Pueblos se dedican á la labranza de los Campos y hacen sus Milpas particulares, no obstante que siembran de comunidad para el sustento de los Sacerdotes, de los Huérfanos, Viudas y Enfermos. ... Algunos se destinan para herreros y carpinteros, que son los oficios más indispensables ... otros se aplican a la Música y aprenden a tocar Guitarra, Violín, Violón y Marimbas, únicos instrumentos de que usan en las fiestas y funciones eclesiásticas á que son bastante afectos, de manera que nunca ha faltado un competente número de Cantores y Músicos en los tres Pueblos... los indios en general son hábiles é industriosos para todos los oficios y para el comercio. En los tres ... pueblos se exercitan en sacar Mastate, beneficiar la Resina del Copé, hilar Pita, hacer mochilas y riendas para frenos de caballo, con cuya industria comercian, vendiendo y revendiendo otros efectos que adquieren de los Indios de la Montaña y de los Ladinos para comprar Reses y Mulas en las haciendas de Chiriquí y Cartago. ... diestros y cuidadosos en el pastoreo de Ganados, para la Conducción de Cabalgaduras, carros y demás Servicio de camino; ... asisten con mucho esmero al viajante ... van presto a traer pescado para su pasagero ... Caza de todo género de animales ... en los Pueblos de la Reducciones se han fundado Hatos (Reygada, 1907, pp. 260-261).

En el caso de Tucurrique, la pobreza era mayor que en otros pueblos:

En el pueblo de reducción de Tucurrique, viendo la suma miseria en que se hallan estos neófitos, les he obsequiado 25 cabezas de ganado menor para que formen un común, dejando dispuesto hagan sus siembras de maíz, frisoles, algodón, \&. y que con su producido se aumente y fomente este fondo. En ninguno de los pueblos de indios hay hacienda alguna de ganado de comunidad, y tal cual particular tiene una ó dos cabezas (Ayala, 1907b, p. 508).

\section{Sobre los Indios de la zona fronteriza (de la Montaña, Gentiles, Infieles, Insumisos) al final de la Colonia}

Casi todas estas poblaciones lograron sobrevivir, en su condición de indígenas, hasta el siglo XX o el siglo XXI, con su identidad étnica; igualmente lo hicieron los pueblos reducidos que estuvieron más alejados del Valle Central (Pacaca -se reconcen aún los indios de Quitirrisí-, Boruca, Térraba, Tucurrique). Los de "la montaña" fueron los guatusos, hoy malecus; desaparecieron votos (que los malecus mencionaban aún en 1970) y ramas en el siglo XIX; ambos fueron clasificados con los guatusos en los informes de los años que se están examinando en este trabajo; posiblemente el asiento de misión más cercano fue Nuestra 
Señora de Garavito; los guatusos permanecieron bastante desconocidos para la sociedad hispano criolla en los años 1800-1830, aunque no eran tan desconocidos para los habitantes de Nicaragua ${ }^{2}$; los cabécares (asientos de misión no permanentes en Chirripó y en San José Cabécar), los bribris y teribes; los chánguenas desaparecen a finales del siglo XIX y principios del XX; desde la Colonia y durante el siglo XIX los límites de Costa Rica por el lado panameño ${ }^{3}$ incluían guaymíes (hoy ngobes y buglé), dorasques y dolegas.

Fray Francisco Reygada (1907) menciona los Cavecras (cabécares); Térrabas del Norte (teribes) cuyas parcialidades son Chunono, Brusí, Drogó y Churquín (Yorkín) y los Talamancas o Viseytas (bribris).

\section{Trajes}

Fray José Mariano Vidaurre (1937; citado por Barrantes, 2004), asevera de los bizeitas, chánguenes y Nortes: "los hombres andan enteramente desnudos, y ordinariamente pintados de diversas figuras y colores, las mujeres apenas usan un braguerillo" (pp. 25-26).

\section{Religión}

Las montañas, el aislamiento y consecuente oportunidad de vivir los indígenas de acuerdo con su propia cosmovisión, están entre los factores que explican las dificultades de conversión y la resistencia de los denominados infieles.

...no se omite ocasión que parezca favorable para reducirlos a la verdadera religión, pues por lo menos se hacen dos ó tres entradas... cada año, emprendiendo a pie el camino de nueve ó diez días por entre riscos y precipicios hasta llegar a

2 La Provincia de Costa Rica reconocía al final de la Colonia y durante la primera mitad del siglo XIX, los límites que aparecen, entre otras fuentes, en la Bula de erección de la diócesis de Costa Rica en la América Central (Santa Sede, 1850): "El territorio de esta nueva Diócesis de Costa Rica será el mismo que comprende... el Estado del mismo nombre, habitado ... por cerca de cien mil almas, el cual se limita al Occidente por el río llamado de la Flor y se extiende por la ribera del Lago de Nicaragua y río de San Juan hasta el lugar donde ése desagua en el Océano Atlántico; al Norte confina con el mismo mar hasta la corriente inferior del río de San Juán y el escudo de Veraguas; al Oriente, desde el antedicho lugar hasta otro río que llaman Chiriquí; y finalmente al Sur se extiende desde el mismo río Chiriquí hasta el otro de la Flor junto a la playa del mar Pacífico" (p. 367).

3 La zona norte incluía indígenas de otras etnias que habían huído del contacto español en las otras regiones de Costa Rica. Hubo varios esfuerzos de búsqueda de estos indígenas a finales del siglo XVIII para la conversión, para establecer haciendas, para encontrar rutas hacia el río Sarapiquí y río San Juan. Solórzano (2013) se refiere a las siguientes expediciones por el área de los guatusos, entre 1800 y 1830: Eusebio Rodríguez (1819); Joaquín Mora (1821); Richard Trevithick (1822); Miguel Alfaro (1826 y 1827). Los guatusos lograron mantenerse muy apartados de los no indígenas durante estos años. 
sus Palenques... procurando atraerlos con regalos de avalorios, hachas, machetes y otras cosas que son de su agrado...

Los cavecras, que están a cargo de los Misioneros... de Orosí, tienen una muy grande aversión á los pueblos, de manera que jamás se acercan á ellos siquiera de paseo, como suelen hacerlo otros Indios Gentiles. ...Los Talamancas, que se nombran también Biseytas, siempre han mostrado su dura cerviz al yugo suave de la Christiandad, aunque á veces profieren algunas palabras que al pareceer dejan esperanzas de su conversión, pero vanas en efecto y que la esperiencia ha enseñado que no nacen del Corazón, conjeturándose de aquí que estos Indios necesitan ser compelidos... Persuade esto un hecho... de 1742 y 1743, en los que hizo algunas entradas ... el Gobernador de Costa Rica, logrando sacar suficiente número de Indios para formar el pueblo de los Tres Ríos,... los que catequizaron los Misioneros de este Colegio hasta ponerlos capaces de ser gobernados por los ordinarios eclesiásticos, como se verificó; notándose que en la primera entrada sacó 123 personas de ambos sexos y en la segunda 314, de los cuales solamente 144 salieron forzados y los restantes voluntarios (Reygada, 1907, 261-263).

Las distancias explicaron el lento progreso:

Doscientas catorze leguas... de León, donde el obsipo tiene su residencia, lo fraguoso del camino, veinte y nueve años transcurridos desde la última vez que se visitó a Costa Rica... el lento progreso de las Conquistas de Infieles que se hazen en las Montañas de Talamanca, fronterizas á esta Provincia... (Ayala et al., 1907, p. 330).

Por lo general, la resistencia al cristianismo se manifestaba en huídas, en apartarse de los misioneros y de las ermitas, pero también en formas más violentas:

habiendo entrado a la montaña... Fr. Apolinar Moreno, con el fin de sacar á dos Indios Cristianos que habían escondido aquellos infieles en otra ocasión que entró el mismo Padre por ver si lograba reducir algunos infieles, han tenido ahora el atrevimiento ... á salir de mano armada á darle de palos al mencionado Padre y á los que le acompañaban, quitándoles cuanto conducían para obsequio y trato con los demás infieles, y que apresaron al Indio Cayetano Navarro, Cristiano (Ayala, 1907a, p. 506). 
Otro ejemplo: “...han salido Indios del Río Yrripó... [quienes] dicen: los otros sus compañeros [piden] le den los Indios que llevó el R. P. Quesada, y que si adonde ellos vuelve lo matan y matan los indios que traiga; y que si no les vuelven los indios acaban con el Pueblo de Tucurrique" (Ayala, 1907c, p. 511). La resistencia indígena manifestada en lo religioso como en otros ámbitos, en la Colonia y posteriormente, ha sido tratatada por Solórzano (2013).

\subsubsection{Guerra}

Fray José Mariano Vidaurre (1937; citado por Barrantes, 2004), expresa: "las naciones son bizeitas, chángüenes, y Nortes, su carácter bárbaro y guerrero, su ejercicio común la caza y ensayarse al arco y flechas, lanzas y macana, para destruirse, esclavizarse mutuamente y robarse las mujeres". Vidaurre (1937; citado por Barrantes, 2004) también afirma que no cuentan "con gloria ni infierno, ni más felicidad que la brutal de los sentidos, ni más heroicidad que matar a sus enemigos, trayendo en testimonio de su valor horadadas las orejas y labios, según el número de cabezas que han cortado” (pp. 77-78).

\subsubsection{Comercio}

Reygada (1907) refiere que:

...los cavecras no necesitan de los Padres Misioneros para surtirse de las cosas que apetecen... [cuentan] con el recurso de Matina y otros parages donde adquieren la Sal, los Perros, las Flechas, \&., á cambio de sus Mastates, Mochilas y Granos... [De los térrabas del Norte] al presente se han reunido los más en la parcialidad de Churquín que habita cerca del Mar; y en el comercio de los Ingleses que vienen de la Isla de San Andrés á la Pesca del Carey en la de Bocatoro, se hallan surtidos de lo que necesitan en las Montañas y tan enamorados de los Ingleses que al tiempo de la Pesca se bajan al mar por ellos y se olvidan entonces de los Parientes que tienen los pueblos, á quienes solían visitar con frecuencia. Pero no es éste sólo el el perjuicio que ocasiona el Comercio de los Ingleses, sino que también los Indios convertidos se huyen de los pueblos por el mismo motivo, y los que no se quedan apóstatas vuelven surtidos de estampados, Polveros, chelecos, chupas, Espejos, Frascos, Tazas de loza fina, Espadines, Sombreros y otras vagatelas que arrebatan la afición de estos miserables (p. 262). 
La venta de esclavos era parte del comercio: Fray Juan de Dios Campos Díez “indicó ... que [en 1803] había comprado a los indios nortes un esclavo viceita y una niña de la misma nación, la cual le vendió su mismo padre" (Barrantes, 2004, p. 34).

\section{Interacción entre las gentes de los pueblos, las de la zona fronteriza y la sociedad his- pana criolla}

\section{Relaciones sociales}

Las relaciones entre tributarios y gentiles se mantuvieron antes y después de la Colonia. En los pueblos de reducción se dio una mezcla étnica semejante a la que ocurría entre las etnias de la zona fronteriza. Aunque era política de los misioneros dejar en cada pueblo principalmente los de una sola etnia, lo cierto es que por motivo de las epidemias se repoblablan, casi siempre de modo forzado, con gente de las montañas; asímismo, porque de estos pueblos huían los reducidos a menudo para refugiarse en localidades de la montaña; también hubo casos de traslados voluntarios (huían de la montaña por el asedio de los misquitos, porque se cristianizaban algunos, porque buscaban cónyuges entre gente de otra etnia, visitas entre ellos, etc. Especialmente los pueblos colindantes tenían actividad de intercambio de productos indígenas y no indígenas relativamente variada. Estas gentes de los pueblos contiguos a las montañas tenían contacto frecuente entre sí. Fray José Mariano Vidaurre (1937; citado por Barrantes, 2004) se refiere a este tema:

Aunque los ... de Térraba y Orosi, parecen capaces de entregarse al ordinario por su civilización pero no se pude todavía verificar, porque el primero no solo sirve de albergue a los ministros, sino que los indios de él y los de la infidelidad tienen parentesco y amistad, lo que conduce a facilitar las entradas a sus palenques, y a que se vayan aficionando a la Christiandad. El de Orosi sirve de puerto a aquellas Reducciones, en él se hacen las provisiones para el divino culto en el otro de Térraba, como para algunos víveres de los Ministros y vestuarios de los neófitos y catecúmenos, a más de que los P.P. de él hacen también su entradas a las rancherías de los infieles a fin de atraerlos a la fe, y sin conservar este será dificultosa la permanencia del otro. Estaban congregados en ambos pueblos a fines del año 1810, mil doscientos cuarenta y dos indios, seis de ellos catecúmenos y los demás neófitos (pp. 77-78). 


\section{2. Las comunicaciones en la zona fronteriza (la montaña)}

En el camino de Cartago a Panamá, el paraje de Savegre, a 40 leguas de Cartago, fuertes vientos y lluvias hicieron caer corpulentos árboles, cerrando el camino. El plan de reparación incluyó a los indígenas de pueblos tributarios:

[los árboles] han cerrado... el camino é interceptado la comunicación con las reducciones de Boruca, Térraba y Guadalupe, que se hallan en los confines de esta provincia, consideré precisa su composición y que debía hacerse por los que más la frecuentan, como son los indios de las tres dichas reducciones, los de la misión de Orosi y los tributarios de la Tobosi y Aserry... (de Acosta, 1907b, p. 282).

El gobernador también incluye la ayuda que deben prestar los ganaderos no indígenas, pero suspende su orden porque considera que a los indígenas se les debe pagar, se dificulta enviarles alimentación y la reparación del camino tardará mucho. Añade:

...es incuestionable la necesidad de rehabilitar el camino ó abrir otro nuevo... no solo queda interrumpido el corto comercio de mulas que esta provincia tiene con la de Panamá, que aunque de poca consideración no tiene otro, sino que... se intercepta la comunicación de toda esta misión de Talamanca, la del corto número de haciendas de ganado que hay hacia aquellla parte y los asuntos del real servicio que pueden ocurrir entre este y aquel reino (de Acosta, 1907b, p. 283).

El gobernador considera la opción de mejorar el camino indígena entre Orosi y Boruca, por el que se traslada la gente a pie en cinco días, para que puedan pasar las mulas. Tampoco se resuelve el problema, precisamente porque: "habiendo comisionado á el efecto á los indios del citado pueblo de Orosi, como los más prácticos por aquella parte, éstos informaron a su regreso que era imposible por ser muchas y muy escarpadas sierras que median entre su pueblo y el de Boruca... nunca podrían traficar por ahí recuas..." (de Acosta, 1907e, p. 295).

Un informe de Tomás de Acosta del año 1803 (de Acosta, 1907d) revela que no es mucho lo que se sabe de la zona fronteriza norte de parte de los no indígenas. El Gobernador duda de un proyecto de camino por 
ese lado. Expresa, con base en documentos que ha visto, que es infructuoso penetrar a la laguna de Granada y al Río San Juan por esa zona, aunque podría ser muy conveniente para la defensa del Castillo Viejo en el San Juan. Agrega:

Los mapas que he visto, y en particular uno de esta provincia, todos ponen la laguna de Granada y río de San Juan confinantes con este gobierno y no distantes de sus volcanes; las noticias que he adquirido de los indios, que son los que más conocimientos tienen de estos bosques, aseguran la proximidad. Lo que varios han observado desde estas alturas y yo desde este volcán tres años hace, confirman que bien sea la laguna ó río citado no están lejos „,. Estas reflexiones me hacen creer que de las citadas embarcaciones se acercó alguna á las costas de esta provincia por aquella parte, y que por haber visto en ellas fogatas ó indios de los infieles Guatuzos, que según la opinión general habitan del oeste al norueste (sic) de esta provincia, entre las cordillera de Puás (sic) y la laguna... (de Acosta, 1907d, p. 287).

Aconseja buscar salida de las poblaciones en la zona dirigiendo el rumbo del sur al sureste "para no encontrar con los infieles antropófagos Guatusos y venir á salir al volcán de esta ciudad [Barva]...” (de Acosta, 1907d, p. 288).

El Gobernador Juan de Dios de Ayala, en 1816, informa haber visitado todas las poblaciones del país, “á excepción del pueblo de Boruca, por la larga distancia y fragoso del camino" (Ayala, 1907b, p. 508).

\section{Después de 1821}

\section{Continuidad}

En lo referente a indígenas, para los años 1821-1830, se podría afirmar que Costa Rica no tuvo un rompimiento drástico con las condiciones prevalecientes en las primeras dos décadas antes de 1821. Tanto en la vida cotidiana, como en los conflictos, lo que se percibe es continuidad o transición lenta hacia lo propio del nuevo estado nación. No fue así porque continuara la situación colonial totalmente: se puede constatar que hubo cambios, como en los ejemplos anteriormente presentados sobre el cambio de las penas en Boruca o sobre el decreto de 1824 relacionado con "los limítrofes"; igualmente en las expresiones despectivas aplicadas a lo colonial y lo español; sin embargo, es de notar que ya en la sociedad colonial se perfilaba la situación republicana. En dicha sociedad coexistían tendencias monárquicas con tendencias liberales respublicanas, pero hubo un cambio notable por el imaginario republicano a partir de 1821 y especialmente después de 1823. Al respecto Juan Rafael Quesada Camacho (2009) concluye: 
...en realidad desde 1812 se había venido produciendo una "revolución silenciosa", esto es, una significativa fermentación ideológica a raíz de todos los cambios efectuados en Cádiz. ... Fermento o levadura que explica la forma en que se produjo la independencia y la particularidad de la constitución de la nación moderna costarricense y el Estado nacional. ... se comprueba por el hecho de que una vez conocida el Acta de Guatemala, los costarricenses actuaron con rapidez y... aprobaron (el $1^{\circ}$ de diciembre de 1821) el Pacto Social Fundamental Interino o Pacto de Concordia... El paso del ciudadano vecino al ciudadano soberano, la asociación entre vida republicana y libertad, explican el que desde diciembre de 1821 el Pacto de Concordia fuera visualizado como "estatuto de la libertad", ...Ejemplo contundente del cambio que provocó el surgimiento de la nación moderna y el republicanismo en Costa Rica, como producto de la independencia, vista ésta no como un capítulo de la historia batalla, sino como un cambio en las mentalidades colectivas, es el protagonismo que desde 1821 adquirió el término ciudadano (p. 16).

Quesada menciona otros ejemplos para confirmar el cambio de mentalidad. Con respecto a la continuidad o el cambio lento en lo indígena, se puede ilustrar con la siguiente cita de Margarita Bolaños:

Los indígenas del Valle Central constituían una minoría hacia 1821 [aproximadamente $12 \%$ de la población del Valle] cuando se decretó la Independencia de España. Pero, por su condición de tributarios de la Corona, ... habían adquirido no sólo el derecho a tener cabildo o municipio, sino también una porción importante de tierra. La posesión del cabildo y de unas dos mil quienientas manzanas o más de tierra, situadas estratégicamente en donde se sembraría café ... más tarde, les permitió ... participar en el juego del poder que se generó después de 1821 . Sin embargo, fue la debilidad política y la paridad de fuerzas entre los distintos sectores que disputaban el poder, lo que les permitió, a los antiguos municipios indígenas participar en el proceso político entre 1821 y 1848, este último año cuando se suprimen la mayoría de los municipios. ... Los municipios indígenas contribuyeron, ... a que la tierra no se concentrara aceleradamente y ... a ampliar la base campesina con un sector proveniente de mestizos sin tierra que comenzaron a ingresar en mayor número a los pueblos indígenas después de 1826 cuando se permitió la residencia al mestizo en [dichos] pueblos. Paradójicamente, los "derechos" adquiridos en la última etapa del gobierno colonial se convirtieron en los bastiones de lucha de las comunidades indígenas. Ellos apoyaron políticamente a aquellos sectores que ofrecieron mantener la tierra comunal y respetar la autonomía de sus municipios (Bolaños, 1998, pp. 159-160). 
Esto sucedía aún en aquellas comunidades que se habían ido ladinizando previamente a 1821, como en los casos siguientes:

Según datos del Obsipo Thiel ... para 1801, en el Valle Central sólo tres de las ocho comunidades indígenas mantenían un grupo importante de no indígenas. Ellas eran La Unión, Pacaca y Barva. En esta última, según sus estimaciones, el 49 \% de su población era mestiza, el $33.5 \%$ indígena y el $10 \%$ era considerada española (Bolaños, 1998, pp. 162-163).

No obstante que los indígenas del Valle Central pudieron participar en alguna medida en la política municipal, tuvieron limitaciones para trascender el espacio político (Ibarra, 1988). No se consideraban suficientemente "civilizados", lo que se puede ejemplificar con esta opinión del Jefe de Estado Mora Fernández:“...la falta de civilización o rudeza de los indígenas de estos pueblos y la costumbre inveterada de vivir sumidos en la ignorancia y la miseria ..." (Meléndez, 1981, p. 59), emitida en 1831, en el caso de dos indígenas fracasados en una cátedra. En el fondo, el permitir el ingreso de no indígenas en sus tierras era una estrategia para disminuirles el acceso a ese recurso a los indígenas, lo que dio como resultado la pérdida gradual pero creciente, paralela al aumento de fincas de café en el siglo XIX. Los indígenas siempre protestaron por esas pérdidas, así como la de otros recursos. También fuera del Valle Central las protestas se presentaron. Un ejemplo fue Nicoya: Ibarra (1988), menciona su caso; protestaron en 1827 (pueblo incorporado a Costa Rica en 1824), pues los ladinos intervenían en la explotación del palo brasil y el caracol de tinte. Además de permitir ladinos y españoles en los pueblos tributarios, otro medio de disminuir las tierras de indígenas fue eliminar los comunes. En el mensaje de Juan Mora Fernández de 1828 se lee:"'los terrenos progresivamente se reducen a dominio particular" (Meléndez, 1981, p. 30). Ya en 1828 se utilizaba el pretexto de que las tierras indígenas eran terrenos ociosos, como aún sucedía durante todo el siglo XX.

Una opinión emitida por el mandatario Juan Mora Fernández en 1831, revela que la zona fronteriza se consideraba difícil de colonizar: "Los ingresos por la venta de tierras baldías cada día desaparecen, y es la razón, porque, agotándose los terrenos útiles, ya no quedan por enajenarse sino los vastos desiertos que quedan al norte y este de la cordillera" (Meléndez, 1981, p. 59). Como en Costa Rica no existen desiertos, se entiende que la referencia significa en ese caso 'terrenos deshabitados'. Otro gobernante, José Rafael de Gallegos, en 1833, reafirma, sobre Turrialba, "la continua reducción de terrenos a dominio particular" (Meléndez, 1981, p. 80).

En el caso de la evangelización, sí hubo interés de parte del nuevo Estado en que no se interrumpiera; se sostenían los frailes, aunque con limitaciones: “... los recoletos tienen ahora a su cargo las reducciones de Orosi, Térraba y Boruca, pero se carece de superior entre ellos. ... El Estado concurre al sostén de los [de hábito] en los pueblos citados ... (Juan Mora Fernández, 1830; citado por Meléndez, 1981, p. 50). 


\section{Comunicaciones después de 1821}

La construcción y reparación de caminos hacia los puertos y hacia los límites con Panamá y Nicaragua se notan en los años previos a 1821, como se ha indicado, pero se mantienen como interés explícito del naciente Estado; ello fue un medio de contacto, de reducción del aislamiento de las áreas fronterizas pobladas con indígenas, pero el interés fueron los caminos en sí, no estas poblaciones:

Es un axioma bien conocido en la economía, que los caminos de ambos puertos deben ser los primeros canales para crear y extender nuestros comercio y agricultura... A este intento también se ha deseado en el Estado tener un camino directo para el comercio del río y puerto de San Juan... una compañía... de Alajuela... abrió una vereda formal... que conduce al mismo río de Sarapiquí... (Juan Mora Fernández, 1830; citado por Meléndez, 1981, p. 37-38).

El Jefe de Estado Mora Fernández, en 1830, igualmente afirma: “ La composición de caminos se repite anualmente con beneplácito de [la población] ... el de Matina fue compuesto generalmente ... [aunque afectado por] la muchedumbre de fangos y grandes cuestas..." (Juan Mora Fernández, 1830; citado por Meléndez, 1981, p. 50).

\section{Continuación del caso de Tres Ríos (La Unión, Nuestra Señora del Pilar)}

Rosa María Durán (2013), aporta los siguientes datos:

1821: ...El 15 de setiembre...se firma la Independencia de España... No hay documentación suficiente para determinar... cual fue la actitud que tomó Tres Ríos ante este acontecimiento... dada su situación geográfica entre San José y Cartago se supone que sus pobladores estaban al tanto de la situación política... y que supieron tomar sus decisiones al lado de San José en los acontecimientos que se dieron en ese año y en los años posteriores.

1823: Tres Ríos se declara en favor del sistema republicano y... de San José. ... se desprende que San José ejerció una gran influencia sobre... Tres Ríos... El 04 de abril las tropas josefinas en su camino hacia Cartago para impedir la unión al imperio mexicano de Iturbide, acamparon en Tres Ríos con el beneplácito de su población.

1824: ... Tres Ríos tenia 113 casas... 273 mujeres y 259 hombres. En total 532 personas. El 13 de diciembre la Municipalidad ... solicita al Juzgado Constitucional ... informe sobre el modo y condiciones en que pasó a Cartago, una imagen de la Inmaculada Concepción que les había sido prestada y que no querían devolver. 
También porque la que les quedó estaba muy fea y esperaban la visita del obispo de la diócesis don Lorenzo de Tristán. ... este año la Municipalidad... propone a los padres de familia que manden a sus hijos a la escuela, ... en San José o en Cartago. Para que aprendan a leer, escribir, contar y los rudimentos de la religión; para que sean hombres útiles a la patria y a la comunidad. Los indígenas cedieron un terreno de su propiedad para que con el producto de su explotación se sostuviera en Tres Ríos una escuela de primeras letras.

1825. El alcalde constitucional de Cartago... decreta que el nombre de Tres Ríos sea cambiado por el de Nuestra Señora del Pilar de La Unión. Que se impondrán multas de uno a cinco pesos a los que no acaten la orden. Este decreto fue llevado ante el Supremo Gobierno, menciona que en el pueblo se han avencindado variedad de indígenas y ladinos, fue dado por don Juan Mora Fernández, Jefe de Estado.

1826. La municipalidad colocó en la Sala de Sesiones, un óvolo de madera con el Escudo de Armas de la República, como prueba de apoyo y obediencia a la naciente nación. 1833 a 1835. Tres Ríos fue frecuentemente visitado por el Jefe de Estado don José Rafael de Gallegos que tenía una finca de café. Para hacer estas visitas tuvo que pedir permiso a la Asamblea Legislativa, la cual se lo concedió” (Durán, 2013, pp. 3-4)

Uno de los documentos que ilustran cómo se fue dando la disolución de los pueblos tributarios del Valle Central proviene de la Municipalidad de la Unión (Tres Ríos), cuando resuelve eliminar la posesión colectiva de las tierras de los indígenas en 1825 (Archivo Nacional de Costa Rica, 1951). En su Acta 30:

...manifiesta el proyecto de reducir a propiedades particulares el terreno que estos indígenas por donacion posean en comun, considerando serles ventajoso el utilizarse exclusivmte ( $\mathrm{sic}$ ), de la porcion que se les designe lo que no sucede poseyendolo asi en comun ... Que los PP Misioneros compraron el terreno y lo donaron al Pueblo (p. X).

Enumeran ventajas, desde su punto de vista, aunque dicen tener el acuerdo indígena para la distribución, de que los indígenas sean poseedores individuales y no colectivos. Agregan "ya los indígenas están bien ladinizados, distinguiéndose de los ladinos en solo el color" (Archivo Nacional de Costa Rica, 1951, p. 116). Resuelven distribuir lotes de 50 varas cuadradas a cada "hombre casado, viudo, viuda, muger sola y á los huerfanos" (Archivo Nacional de Costa Rica, 1951, p. 117) sin perjuicio de dejar libre una manzana para la iglesia, otra para la plaza, cincuenta varas para la Sala Municipal, y lo mismo para la casa de enseñanza pública. Además de los lotes de vivienda, se adjudica una manzana para cultivos. Añaden que el pueblo alimenta 300 y más ladinos, y solo 100 indígenas. Denominan "tiempos de barbarie" los años de la Colonia y explican la explotación que hacían del indígena "sus amos los tiranos de España" (Archivo Nacional de 
Costa Rica, 1951, p. 118). Se argumenta una serie de factores de unidad existentes entre indígenas y ladinos. Se traza el cuadrante del pueblo. En 1826 informan de la entrega de documentos de posesión, con los nombres de los concesionarios precedidos del título Ciudadano o Ciudadana (abreviado Cno., Cna.).

\section{La situación de frontera}

\subsection{Frontera como categoría de análisis}

La frontera indígena se ha utilizado como categoría analítica en América. Según lo señala Comas (s.f.), se suelen emplear definiciones turnerianas, que son aplicables en Costa Rica 1800-1830: a) borde exterior del asentamiento o límite externo de la ocupación: esto en el caso de la separación entre áreas habitadas por la sociedad hispano criolla y las areas habitadas por indígenas; b) lugar de encuentro de culturas indígena e hispano criolla: esto en los pueblos reducidos, pues mediante su capacidad para transformarse en cristianos, hispanohablantes, y aprender otras artes de la sociedad no indígena, son separados para su utilización como mano de obra y tributo. Especialmente en los pueblos colindantes conviven: los misioneros y los funcionarios del gobierno; los indígenas cristianos y los denominados infieles, a menudo de varias etnias tanto los unos como los otros; y otros residentes no indígenas; c) área de tierras libres en continuo receso: fue el caso de la expansión costarricense no indígena hasta el presente, puesto que las tierras ocupadas por indígenas se han tomado por terrenos baldíos o mal aprovechados. Los territorios aborígenes son percibidos como "desiertos" sobre los cuales las poblaciones criollas avanzan para establecer la civilización (al presente se dice el progreso, o el desarrollo).

La categoría analítica frontera implica analizar el tratamiento que los investigadores del tema dan a la otredad y con base en esto Comas (s.f.) interpreta la historiografía de la frontera; parecería esto aplicable igualmente a la información como está escrita por misioneros y funcionarios en las fuentes, en las que se reflejan los tres abordajes identificados por esta autora: tradicional (oposición barbarie-civlización), intermedio (el frente de avance de la sociedad criolla), y reciente (fronteras como espacio social). Los tres abordajes emplean diferentes concepciones de lo indígena. En las fuentes aparece lo tradicional, en que "los otros" de la montaña son salvajes, infieles; la contraposición barbarie-civilización no desaparece totalmente en la situación post colonial, se mantiene en el siglo XIX y en variables medidas posteriormente. El abordaje reciente señalado por Comas enfoca la frontera no como límite separador sino como una área de interrelaciones entre ambas sociedades. Las fuentes en el presente trabajo ilustran formas de interacción entre grupos indígenas y entre éstos

y la sociedad no indígena. Al respecto, Goicovich (2006) destaca la permeabilidad de las fronteras sociales, refiriéndose al contacto cotidiano entre clases urbanas chilenas al final de la Colonia, no obstante que en el sistema la separación entre las clases pretendía ser rígida. Esta permeabilidad se observa en Costa Rica, tanto entre los mismos indígenas, como entre ellos y los no indígenas, y es aplicable en lo sociocultural y, 
a pesar de los obstáculos a la accesibilidad debidos al clima y tipo de terreno, en lo geográfico. El abordaje intermedio está relacionado con fuentes donde se enfatiza en el avance de la población no indígena, como fue la frontera agrícola, prestando alguna atención a la etnografía indígena.

Las fronteras tienen sus orígenes en requerimientos sociales (Lattimore, 1968): Los indígenas en pueblos y en "la montaña" se mantuvieron en las márgenes de la sociedad hispano criolla porque se les atribuyó inferioridad; en relación con las otras clases, sus haberes materiales eran muy exiguos; por otra parte, al asumirse que los indígenas eran pocos (lo eran, pero hacían uso de campos de cultivo y de bosques en su modo de vida en forma más amplia de lo que se admitía), o interiorizando la idea de que esos habitantes no existían, se estableció la percepción de una frontera agrícola para la expansión. A los indígenas de los pueblos, les era imposible salir de estos reductos donde les habían asignado solar y vivienda para ocupar espacios donde residían las otras clases sociales del país, en terrenos que alguna vez fueron de los indígenas; en su estatus indígena seguían produciendo artesanías, mano de obra, y productos agrícolas canjeables en la sociedad no indígena; los indígenas dispersos en la montaña no ofrecían, en la República, mano de obra permanente, aunque en algunos casos eran útiles en la construcción y mantenimiento de caminos, o en haciendas. Una vez establecida la situación de frontera por razones socioculturales, los factores geográficos adquieren relevancia: la distancia de los centros urbanos; las dificultades de acceso por cualquier vía de comunicación debidas al clima y a obstáculos del terreno.

Las fronteras, aunque entendidas como espacios de contacto, a su vez generan autonomía en grados mayores o menores, lo que permite a las gentes persistir con características propias por periodos que se prolongan según las variaciones en las mismas fronteras. José de Souza Martins (1996; citado por Zusman, 1999), ha defindo la frontera como el lugar de la alteridad y lo que caracteriza a la situación de frontera es el conflicto social. En ese sentido, la frontera entre lo indígena y lo no indígena en Costa Rica, siempre ha sido conflictiva, aún cuando igualmente siempre hubo ejemplos de cooperación mutua y de convivencia más o menos pacífica entre los dos tipos de sociedad que se han enfrentado históricamente. En las fronteras en contacto, de inclusión y no de exclusión (Lattimore, 1968), ambos comportamientos toman lugar. Para el caso entre lo hispano criollo y lo indígena, lo anterior concuerda con Pulido (1999), quien adapta la noción de "frentes culturales", relacionándola con una "visión para el análisis de las fronteras culturales, por tener el frente el sentido de línea divisoria o de frontera cultural en la cual se tocan, se juntan, se rozan y se interpenetran culturas de grupos y clases sumamente diferentes, según un modelo de zonas de fusión..." (p. 17). Si se considera la situación indígena de 1800 a 1830 en Costa Rica, es possible sugerir que ocurre lo que Pulido (1999) denomina un "sistema simple", menos susceptible a fluctuaciones provenientes del entorno, que en su dinamismo tienden al equilibrio en vez de la inestabilidad, por estar definidas las fronteras con alguna claridad, y de esta manera esos sistemas pueden "rechazar" o "defenderse" contra fluctuaciones que atenten contra su estabilidad. Se podría extender esta explicación a la permanencia de las situaciones de frontera en Costa Rica, entre lo indígena y lo hispano criollo, por lo menos hasta una buena parte del siglo XX. 


\section{A manera de conclusión}

Para concluir, la siguiente es una comparación de las sociedades indígenas, en sus rasgos de frontera, en los primeros años de la emancipación, con los correspondientes al carácter fronterizo de Costa Rica como país, resumidos al inicio del presente trabajo: Se repiten diez de las 12 caracterísicas. En dos no se repiten (puntos 5 y 8), pero se reemplazan por sendas características de frontera igualmente.

1. Escasa población: Se estima en $10 \%$ a $15 \%$ de la población total del país.

2. Prolongada situación de frontera: Fronteras sociales y geográficas desde el inicio de la Colonia, que en diversos grados y según el grupo se prolonga hasta el siglo XX. De hecho, permanecen ejemplos en el siglo XXI.

3. Conjunto de condiciones consideradas desventajosas: aplica lo enumerado para el país en el punto 3 al inicio. Por ejemplo, la falta de moneda en circulación: aún en el siglo XX era sorprendente la escasez monetaria en comunidades indígenas.

4. Autonomía: en los pueblos, hubo espacio de maniobra, con respecto a la sociedad hispano criolla, en el accionar de cabildos. Se mantuvieron identidades comunitarias indígenas por menos tiempo en las cercanías de la capital, San José (mediados siglo XIX); por algo más de tiempo en los alrededores de Cartago (hasta principios del siglo XX); hasta los siglos XX y XXI, en los pueblos colindantes; hasta el siglo XXI en las etnias de "la montaña". En estas últimas se dio mayor autonomía en el mantenimiento de patrones materiales de origen indígena o de cultura "apropiada"; y no materiales (por ejemplo, sistemas de parentesco e idioma propios, cosmovisión aborigen).

5. Economía no integrada: la separación por regiones aplica en el nivel de país pero no en el de las comunidades o etnias indígenas. Sin embargo, un rasgo de frontera fue que predominó la economía de subsistencia, tanto en los pueblos como en "la montaña".

6. Indígenas escasos y dispersos. Se repite todo lo aplicable al país (véase este punto 6 al inicio de este trabajo).

7. Campesinado libre: Frontera agrícola. Se repite lo del escaso control de factores naturales. Después de 1821 los indígenas de los pueblos del núcleo Valle Central van cambiando de ser campesinos de comunidad corporativa colonial al campesinado libre, conforme se van privatizando sus tierras, proceso que empieza antes de 1830 y culmina en el último tercio del siglo XIX; las comunidades dejan de ser exclusivas para ellos, además en cada una son minoritarios; en los pueblos colindantes y en los de "la montaña", la campesinización no ocurre en el siglo XIX en el tanto que la dependencia de centros urbanos es mínima o está ausente. Su lucha por sus tierras de cultivo, de tenencia familiar o individual, y bosques de uso colectivo, así como su gradual campesinización libre, es un proceso observable a lo largo del siglo XX. En lo que respecta a la existencia de una frontera agrícola, la situación es inversa a la de la sociedad hispano criolla, pues el campesinado de ésta, y otros sectores, avanzan sobre las tierras indígenas, como lo venían haciendo desde el siglo XVI, dando lugar a pérdidas de ellas y a una constante resistencia. 
8. Mundo urbano en cierne: No aplicable, no porque no haya existido algún tipo de relación con centros urbanos, sino porque éstos no eran indígenas. Sin embargo, la ruralidad de las comunidades indígenas concuerda con la condición de las fronteras nacionales previas a los años 1950.

9. Más limitada burocracia. Limitado número de funcionarios y religiosos.

10. Dependencia de centros, necesitad de vínculos externos: aumenta, pero muy gradualmente.

11. Predominio de la comunicación oral. Relaciones cara a cara, de parentesco y vecindad. Después de 1821 el alfabetismo aumentó muy gradualmente. En esto hay una diferencia del núcleo Valle Central con los "pueblos colindantes" y "la montaña", donde la escolaridad es principalmente un esfuerzo a partir del siglo XX.

12. Mayor nivelamiento social que en los centros rectores. Entre los indígenas mismos las relaciones son igualitarias, han prevalecido las relaciones de parentesco (se reconocen diferencias de rango y riqueza en las familias, pero no constituyen clases). Con respecto a la sociedad hispano criolla, ésta mantiene distancias variables de clase.

\section{Referencias bibliográficas}

Archivo Nacional de Costa Rica. (1951). Repartición de tierras a los indígenas del pueblo de la Unión, Año de 1825. Revista del Archivo Nacional, 15(4-6), 115-123.

Ayala, J. de D. (1907a). Carta de D. Juan de Dios de Ayala al padre Fray José María Núñez, presidente de las reducciones de Costa Rica. En L. Fernández (comp.), Colección de Documentos para la Historia de Costa Rica (Tomo X, pp. 505-506), Barcelona: Imprenta Viuda de Luis Tasso.

Ayala, J. de D. (1907b). Informe de D. Juan de Dios de Ayala. En L. Fernández (comp.), Colección de Documentos para la Historia de Costa Rica (Tomo X, p. 508). Barcelona: Imprenta Viuda de Luis Tasso.

Ayala, J. de D. (1907c). Carta de D. Juan de Dios de Ayala á fray José Vicente Quesada. En L. Fernández (comp.), Colección de Documentos para la Historia de Costa Rica (Tomo X, p. 511). Barcelona: Imprenta Viuda de Luis Tasso, 1907.

Ayala, J. de D., de Bonilla, J. F., Marchena, M., de Oreamuno, J., Oriamuno, S., Carazo, N. y de Peralta, J. M. (1907). Representación del ayuntamiento de Cartago á S.M. para que nombre obispo de Costa Rica al deán D. Juan Francisco Vilchez. En L. Fernández (comp.), Colección de Documentos para la Historia de Costa Rica (Tomo X, pp. 330-331). Barcelona: Imprenta Viuda de Luis Tasso.

Barrantes, C. (2004). Orígenes de la Diócesis de San Isidro de El General: una historia eclesiástica regional. San José: Imprenta Nacional.

Bolaños, M. (1998). La colonia y la resistencia indígena en la configuración económica y cultural de las sociedades costarricense y guatemalteca del siglo XIX. En M. E. Bozzoli, R. Barrantes, D. Obando y M. Rojas (comps), Memoria del primer congreso científico sobre pueblos indígenas de Costa Rica y sus fronteras (pp. 153-172). San José: UNICEF, UNED, UCR, EUNED. 
Bozzoli, M. E. (2005). Características de la sociedad costarricense en los albores de la emancipación. IX Congreso de la Asociacion de Academias Iberoamericanas de la Historia (pp. 571-586). Madrid: España.

Carrillo, C. Nicolás (Presidente) y Zeledón, C. Pedro (Secretario). (1962 [1824-1825]). Disposiciones sobre trato a los indígenas. Libro de Actas de la Comisión de justicia, negocios eclesiásticos e instrucción pública, 1824-1825. Revista de los Archivos Nacionales, XXVI(1-6).

Comas, M. F. (s.f.). La cuestión del otro en la construcción historiográfica de la frontera (Argentina). Recuperado de http://www.monografias.com/trabajos63/construccion-historiografica-frontera/construccion-historiografica-frontera.shtml

de Acosta, T. (1907a). Informe del gobernador D. Tomás de Acosta sobre los indios tributarios de la provincia de Costa Rica. En L. Fernández (comp.), Colección de Documentos para la Historia de Costa Rica (Tomo X, pp. 277-278). Barcelona: Imprenta Viuda de Luis Tasso (Original de 1802).

de Acosta, T. (1907b). Carta del gobernador de Costa Rica sobre la necesidad de componer el camino que conduce á Panamá ó de abrir otro nuevo. En L. Fernández (comp.), Colección de Documentos para la Historia de Costa Rica (Tomo X, pp. 282-283). Barcelona: Imprenta Viuda de Luis Tasso (Original de 1802).

de Acosta, T. (1907c). Subdelegaciones de justicia e indios tributarios, provincia de Costa Rica. En L. Fernández (comp.), Colección de Documentos para la Historia de Costa Rica (Tomo X, pp. 284-285). Barcelona: Imprenta Viuda de Luis Tasso.

de Acosta, T. (1907d). El gobernador de Costa Rica informa sobre el nuevo camino propuesto por D. José Ramírez para comunicar esta provincia con la de Nicaragua. En L. Fernández (comp.), Colección de Documentos para la Historia de Costa Rica (Tomo X, pp. 286-288). Barcelona: Imprenta Viuda de Luis Tasso.

de Acosta, T. (1907e). El gobernador de Costa Rica contesta al presidente de Guatemala sobre el proyectado camino á Panamá. En L. Fernández (comp.), Colección de Documentos para la Historia de Costa Rica (Tomo X, pp. 295-296). Barcelona: Imprenta Viuda de Luis Tasso.

de Acosta, T. (1907f). Informe de D. Tomás de Acosta sobre las reducciones de indios. En L. Fernández (comp.), Colección de Documentos para la Historia de Costa Rica (Tomo X, p. 297-298). Barcelona: Imprenta Viuda de Luis Tasso.

del Castillo, F. (1907). El diputado por Costa Rica Florencio del Castillo propone á las cortes la erección de un obsipado en esta provincia. En L. Fernández (comp.), Colección de Documentos para la Historia de Costa Rica (Tomo X, pp. 411-414). Barcelona: Imprenta Viuda de Luis Tasso.

Durán, R. M. (2013). Cronología. La Unión, Cartago: Municipalidad de la Unión. Recuperado de http:// www.launion.go.cr/index.php?option $=$ com_content\&view=article\&id=427\&Itemid=253

Goicovich, F. (2006). La permeable frontera de la sociedad finicolonial: una aproximación al uso jurídico del imaginario social (Santiago de Chile, 1804). Revista Escuela de Historia, 1(5), 3-24.

Ibarra, E. (1988). Los gobernantes y la cuestión indígena en Costa Rica: el peso del legado colonial (18211949). En M. E. Bozzoli, R. Barrantes, D. Obando y M. Rojas (comps), Memoria del primer congreso científico sobre pueblos indigenas de Costa Rica y sus fronteras (pp. 409-427). San José: UNICEF, UNED, UCR, EUNED. 
Lattimore, O. D. (1968). The frontier in history. En R. O. Manners y D. Kaplan (comp.), Theory in Anthropology (pp. 374-386). Aldine Publishing Company, Chicago.

Meléndez, C. (comp.). (1978). Documentos fundamentales del siglo XIX. San José: Editorial Costa Rica.

Meléndez, C. (comp.). (1981). Mensajes presidenciales, 1824-1829 (Tomo I). San José: Editorial Texto.

Pulido, O. (1999). Hegemonía y cultura. Introducción a las estructuras culturales disipativas. Santafé de Bogotá: Corporación Colombiana de Estudios Antropológicos para el Desarrollo (Informe final. Proyecto: 7228-10-002-89. Contrato 123-91).

Quesada, J. R. (2009). Modernidad política e independencia: El caso de Costa Rica. XI Congreso de Academias Iberoamericanas de Historia. Quito.

Reygada, F. (1907). El guardián del colegio apostólico de misioneros franciscanos de Nueva Guatemala informa a S.M. sobre el estado de las reducciones y conversiones que están a cargo del referido colegio. En L. Fernández (comp.), Colección de Documentos para la Historia de Costa Rica (Tomo X, pp. 258-265). Barcelona: Imprenta Viuda de Luis Tasso.

Santa Sede. (1850). Bula de erección de la diócesis de Costa Rica en la América Central. Vaticano: Santa Sede.

Solórzano, J. C. (2013). Los indígenas en la frontera de colonización, Costa Rica 1502-1930. San José: EUNED.

Thiel, B. A. (1902). Monografía de la polación de Costa Rica en el siglo XIX. Revista de Costa Rica, I, $1-52$.

Zusman, P. (1999). Representaciones, imaginarios y conceptos en torno a la producción material de las fronteras. Reflexiones a partir del debate Hevilla-Escamilla. Revista Bibliográfica de Geografía y Ciencias Sociales, 149. Recuperado de http://www.ub.edu/geocrit/b3w-149.htm 


\section{ANEXO 1}

\section{Bibliografía sobre las características de la sociedad costarricense como sociedad fronteriza en 1821}

Acuña, V. H. y Molina, I. (1991). Historia Económica y Social de Costa Rica (1750-1950). San José: Editorial Porvenir.

Acuña, V. H. (2002). La invención de la diferencia costarricense, 1810-1870. Revista de Historia, 45, 191228.

Alvarez, R. R. Jr. (1995). The Mexican-US border: the making of an Anthropology of Borderlands. Annual Review of Anthropology, 24, 447-470.

Balandier, G. (1963). El concepto de "situación” colonial. En G. Balandier, Sociologie actuelle de l'Afrique Noire (pp. 3-38). París: Bibliothèque de Sociologie Contemporaine, Presses Universitaires de France (Traducción de Juan Comas).

Blanco, R. (1971). La iglesia y su situación dentro del Reino de Guatemala en el ocaso de la dominación española. R. Blanco (ed.), Centroamérica en las vísperas de la Independencia. 1821-1971 (pp. 203238). San José, Costa Rica. Editorial Trejos Hermanos.

Baudot, G. (1990). La frontera imaginada. Fronteras políticas y fronteras imaginarias en la fundación de la América Virreinal. Memoria del Congreso Internacional sobre fronteras en Iberoamérica ayer y hoy (Tomo I, pp. 33-45). Baja California: Universidad Autónoma de Baja California.

Bozzoli, M. E. (1971). La diferenciación social en Centroamérica al final del siglo XVIII y durante las primeras décadas del siglo XIX. R. Blanco (ed.), Centroamérica en Visperas de la Independencia. 1821-1971 (pp. 73-131). San José: Editorial Trejos Hermanos.

Bozzoli, M. E. (1977). La frontera agrícola de Costa Rica y su relación con el problema agrario zonas indígenas. Anuario de Estudios Centroamericanos, 3, 225-234.

Bustamante, T. (1996). La ciudad de San José. Ensayo histórico. San José: Municipalidad de San José.

Campos, L. M. (1980). La municipalidad de San José en la formación del Estado de Costa Rica: 18141841 (Tesis de licenciatura inédita). Universidad de Costa Rica, San José, Costa Rica.

de Vos, J. (1990). Teoría y práctica del concepto de frontera: el caso de México. En A. F. Buenrostro (ed.), Memoria del Congreso Internacional sobre fronteras en Iberoamérica ayer y hoy (Tomo II, pp. 192199). Mexicali, Baja California Norte, México: Universidad Autónoma de Baja California.

Fábregas, A. (1990). Teoría y práctica del concepto de frontera: El caso de México. En A. F. Buenrostro (ed.), Memoria del Congreso Internacional sobre fronteras en Iberoamérica ayer y hoy (Tomo I, pp. 65-76). Mexicali, Baja California Norte, México: Universidad Autónoma de Baja California.

Fonseca, E. (1983). Costa Rica colonial. La tierra y el hombre. San José: EDUCA.

Gonzalez, L. (1991). Geopolítica de las fronteras latinoamericanas. En A. F. Buenrostro (ed.), Memoria del Congreso Internacional sobre fronteras en Iberoamérica ayer y hoy (Tomo I, pp. 79-91). Mexicali, Baja California Norte, México: Universidad Autónoma de Baja California.

Herzog, L. A. (1990). The transformation of boundaries in the Americas. En A. F. Buenrostro (ed.), Memoria del Congreso Internacional sobre fronteras en Iberoamérica ayer y hoy (Tomo I, pp. 52-64). Mexicali, Baja California Norte, México: Universidad Autónoma de Baja California. 
Lattimore, O. D. (1968). The frontier in History. R. O. Manners y D. Kaplan (comps), Theory in Anthropology (pp. 374-386). Chicago: Aldine Publishing Company.

León, J. 1997. Evolución del comercio exterior y del transporte marítimo de Costa Rica. 1821-1900. San José: Editorial del la Universidad de Costa Rica.

Mathai, H. (1990). El Congreso Internacional sobre fronteras de Iberoamérica. Ayer y hoy: ¿Un reto a la humanidad?. En A. F. Buenrostro (ed.), Memoria del Congreso Internacional sobre fronteras en Iberoamérica ayer y hoy (Tomo II, pp. 327-335). Mexicali, Baja California Norte, México: Universidad Autónoma de Baja California.

Meléndez, C. (1971). Los problemas de la vida cultural en el reino de Guatemala en la época de la Ilustración. R. Blanco (ed.), Centroamérica en las vísperas de la Independencia. 1821-1971. San José, Costa Rica. Editorial Trejos Hermanos, 171-199.

Meléndez, C. (1977). Costa Rica: tierra y poblamiento en la colonia. 183-199. San José: Editorial Costa Rica.

Molina, I. (1991). Costa Rica, 1800-1850. El legado colonial y la génesis del capitalismo. San José: Editorial de la Universidad de Costa Rica.

Pérez, H. (1988). La población de Costa Rica según el Obispo Thiel. Avances de Investigación, 42, 1-13.

Pérez, H. (1997). Estimaciones de la población indígena de América Central (del siglo XVI al siglo XX). En L. Rosero, A. Pebley y A. Bermúdez (eds), De los mayas a la planificación familiar: demografía del Istmo (pp. 25-35). San José: Editorial de la Universidad de Costa Rica.

Ureña, G. (1971). Centroamérica en las vísperas de la Independencia. 1821-1971. San José: Editorial Trejos Hermanos.

Wolf, E. R. (1975). Los Campesinos. Calabria, Barcelona: Editorial Labor, S.A.

Zelaya, C. J. (1971). Repercusiones inmediatas de la independencia en Centroamérica. R. Blanco (ed.), Centroamérica en las vísperas de la Independencia. 1821-1971 (pp. 313-340). San José: Editorial Trejos Hermanos. 